\title{
Multidisciplinary management of breast cancer
}

\author{
Anne-France Leclerc ${ }^{1,2^{*}}$, Guy Jerusalem ${ }^{3}$, Martine Devos ${ }^{4}$, Jean-Michel Crielaard ${ }^{1,2}$ and Didier Maquet ${ }^{1,2}$
}

\begin{abstract}
Breast cancer, with an increasing incidence, is the most frequently diagnosed cancer in women worldwide. The treatments proposed, generally a combination of surgery, radiotherapy, chemotherapy, endocrine therapy and/or targeted therapy, are constantly improving, allowing a reduction in the mortality rate, but they are still causing many side effects, not only early but also late, which leads us to consider the post-cancer period as a chronic condition. Side effects, reviewed in this commentary, may affect physical functions, psychological status, social situation, body composition, well-being and quality of life of the patient. In view of the extent of these areas in which side effects of breast cancer and of its treatments can be found, the supportive care offered at the end of treatment need to be multidisciplinary. Different supportive care interventions may be proposed to the patients such as psychological and behavioral interventions, complementary therapies, diet interventions, physical activity/rehabilitation or also physiotherapy interventions for example, all having shown some beneficial effects in the literature. The benefits of these supportive care interventions are thereby already established and they are described in this article, but others studies will be needed to clearly define indications and most optimal modalities of application to reduce side effects and improve quality of life of patients.
\end{abstract}

Keywords: Breast cancer, Public health issue, Side effects, Multidisciplinary supportive care

\section{Background}

Because of its incidence, the incurred treatments and especially its multiple clinical and social consequences, breast cancer constitutes a real public health issue.

This cancer remains the most frequently diagnosed in women worldwide with, among others, 1380000 new cases reported in 2008 ( $23 \%$ of all cancers) and its incidence continues to rise $[1,2]$.

Different treatments may be proposed, generally a combination of surgery, radiotherapy, chemotherapy, endocrine therapy and/or targeted therapy. Their effectiveness is constantly increasing, allowing a reduction in mortality [3, 4]. Thereby, between 1992 and 2002 for example, the death rate from breast cancer has decreased by $13,4 \%$ in Europe for women of all ages and by $16,7 \%$ for those aged 35 to 64 [5].

\footnotetext{
*Correspondence: af.leclerc@ulg.ac.be

'Department of Sports and Rehabilitation Sciences, Liège University, Allée des Sports 4 - B21, 4000 Liège, Belgium

2Department of Physical Medicine, Liège University Hospital, Avenue de I'Hôpital 1 - CHU B35, 4000 Liège, Belgium

Full list of author information is available at the end of the article
}

However, despite this progress, breast cancer and its treatments are still causing many psychological, physical, and social side effects, not only early but also late, which leads us to consider the post-cancer period as a chronic condition. In view of the extent of the areas in which side effects of breast cancer and of its treatments can be found, the supportive care offered during and at the end of treatment need to be multidisciplinary.

We will thus, in this paper, review the various treatmentrelated side effects and the different supportive care interventions aiming to improve them.

\section{Main text \\ Side effects of breast cancer and of its treatments Surgery}

Surgery, including radical mastectomy and lumpectomy, associated or not with axillary dissection, remains the centerpiece of breast cancer treatments [6]. Although the techniques continue to improve, various side effects can be observed. The most common complication encountered directly after breast surgery is wound infection, with an incidence of 4,34\% 30 days after radical 
mastectomy and 1,97 \% after lumpectomy with axillary dissection [7]. Cardiac and pulmonary complications are uncommon with a rate of $0,12 \%$ after mastectomy and $0,66 \%$ after lumpectomy and axillary dissection [7]. Similarly, central nervous system complications are rare with rates of 0,12 and $0,07 \%$ respectively and the urinary tract infection rates are 0,66 and $0,14 \%$, respectively [7]. Then, surgery remaining a mutilating action in the eyes of patients [6], the image of themselves may be impaired and particularly after radical mastectomy $[8,9]$. Similarly, sexual functioning $[8,9]$ and role in society [9] also appear sometimes altered. Finally, surgery is also found responsible for fatigue and pain [10].

Axillary dissection can cause additional side effects including lymphedema, numbness, loss of strength and reduction of arm movement amplitude $[8,10-12]$ reducing the quality of life $[8,12]$. The incidence rate published for lymphedema varies between $2 \%$ and $65 \%$ depending on the surgical technique, the axillary sampling method and the use of chemotherapy and radiotherapy [13].

\section{Radiotherapy}

Short-term side effects of radiation therapy are erythema observed in over $50 \%$ of women [14-16], the dry peeling in 6 to $10 \%$ of cases, or wet in more than $50 \%$ of cases $[10,14-16]$, fatigue $[10,15,16]$ more or less pronounced depending on the treatment history and present in over $50 \%$ of women [14], but also edema of the subcutaneous fat $[10,16]$, esophagitis following irradiation of the mammary chain [16], hyperpigmentation $[10,15,16]$, myelosuppression [14], pain [10, 15, 17] as well as anxiety, depression and decreased quality of life [14].

The long-term effects, however rare, include lymphedema of the arm $[10,12,16]$ present in 6 to $10 \%$ of patients after lymph node irradiation [14], subcutaneous fibrosis with possible telangiectasia $[16,17]$ in 10 to $50 \%$ of cases [14], the pulmonary disorders including pneumonia with fever, cough and breathlessness $[10,16]$ with an incidence of less than $1 \%$ [14], brachial plexitis $[10,15-17]$ as well as heart problems such as arrhythmias, pericarditis, ischemic heart disease and myocardial infarction $[10,16,17]$ again present in less than $1 \%$ of cases [14].

\section{Chemotherapy}

Chemotherapy is an important systemic treatment in the management of breast cancer. Depending on the drugs administered to the patient, it can cause various side effects including asthenia [10,14,18-22] which is the most common. Asthenia is, indeed, encountered in 70 to $100 \%$ of patients during the course of chemotherapy $[21,23]$, but also thereafter $[18,19,21]$. The intensity of fatigue appears stable during treatment $[19,21]$ and
$60 \%$ of patients present a moderate to severe level of fatigue [23].

Alopecia is another side effect often encountered in the case of chemotherapy $[14,17,18,21,24]$ and altering the self-image of women [22]. Nausea and vomiting $[14,18,21,22,24]$, diarrhea [14, 18, 22], leucopenia and neutropenia within days of each cycle [10, 14, 24, 25], infection $[18,25]$ and the appearance of neurological toxicity with motor and sensory peripheral neuropathies mainly caused by taxanes $[10,14,24,25]$ are other side effects experienced by the patients. In addition, weight gain $[10,14,18,21,24]$ and ovarian failure resulting in menopausal symptoms including vaginal dryness, hot flashes, dyspareunia, sleep disorders and/or osteoporosis are other frequently observed side effects $[10,14,18,20,24,26]$. Similarly, pain $[10,14,18,21]$, heart problems $[10,14]$, pulmonary problems [10], cognitive dysfunction with difficulties in memory, concentration and language $[10,14,20,24]$, anxiety and finally depression $[21,27]$ are other complications of chemotherapy that adversely affect the quality of life of patients $[8,14,22,25,27]$.

\section{Endocrine therapy}

Like other treatments, endocrine therapy may cause side effects consisting mainly in menopausal symptoms: vaginal dryness, hot flashes, dyspareunia, sleep disorders or decreased bone density and increased risk of bone fracture $[10,14,17,26]$. Endocrine therapy may also cause pain, fatigue, an increase in body weight and vasomotor symptoms $[10,14]$. Other gynecological and sexual problems are also observed: vaginal discharge, mucosal atrophy, loss of libido and dyspareunia [10, 28].

\section{Targeted therapy}

Finally, targeted therapy or immunotherapy is indicated in the breast cancer treatment if there is an overexpression of the HER 2 protein ( 15 to $20 \%$ of cases) and/or an amplification of the gene $[29,30]$. Although the therapy is thus more selective, it unfortunately also generates adverse effects. Depending on the drug used, nausea [31, 32], diarrhea [31, 32], fatigue [32], headache [32], fever [29, 30, 32], cardiac side effects [29, 30,32] and dermatological disorders [31,32] may appear.

In summary, therapy of breast cancer and outcome is improving but side effects are still frequent and are best managed by a multidisciplinary team.

\section{Supportive care}

Supportive care aim to improve the quality of life of the patient by different interventions including symptom control, psychological and social supports, physical rehabilitation, educational needs and sometimes the end of life care, which requires a multidisciplinary cooperation and coordination [33-35]. 
Thus, to meet the patient's needs, we will discuss different supportive care interventions that can provide help and support and which have already been evaluated in several clinical.

\section{Psychosocial and behavioral interventions}

Different systematic reviews and meta-analyses have already analyzed the benefits provided by psychosocial and behavioral interventions to patients who have been treated for breast cancer [36-42]. These interventions include the terms "individual, group or couple psychotherapy, psychosocial therapy, psychoeducation, emotional and social support group, cognitive behavioral therapy, health education and telephone or oral counseling and support". Although they vary in terms of content, duration, frequency and modality of access for the patient, these interventions have a positive impact on emotional or psychological distress [36, 39, 40, 42], anxiety [36, 37, 39], depression [36, 37, 39, 41], fatigue [37], sleep disorders $[43,44]$, body-image [37], stress [37, 39], relationship functioning [40] and on quality of life [36, 37, 39-41].

\section{Complementary therapies}

In complementary therapies, we include relaxation, meditation, yoga, music therapy, stress management and massage. These interventions may also be recommended as supportive care options during and/or after breast cancer treatment because they also show positive effects on anxiety [36-38], depression [36-38], emotional distress [36], mood disorders [38], stress [37, 38], fatigue $[37,38]$, sleep disruption [38, 44] and quality of life $[36,38]$. However, as psychosocial and behavioral interventions, these interventions should be recommended based on professional judgment and patient preferences.

\section{Diet intervention}

Overweight or obesity at the time of diagnosis is a poor prognosis factor and may be associated with a variety of undesirable outcomes such as an increase in the risk of recurrence and disease-specific or overall mortality [45-48]. Moreover, weight gain is a common side effect after chemotherapy $[10,14,18,21,24]$ and/or endocrine therapy $[10,14]$ and it seems to be the result of an increase in adipose tissue mass [45]. To prevent this weight gain and to improve food choices, the American Cancer Society wrote a report in which they discuss nutrition guidelines for cancer survivors [45]. According to this guideline, breast cancer survivors should try to maintain a healthy weight by eating a balanced diet and by practicing regular physical activity. Diets should emphasize vegetables and fruits, have low amounts of saturated fats and include sufficient dietary fiber [45, 47]. Furthermore, other studies show the efficacy of in-person and telephone counseling/nutrition education in weight loss strategies and dietary improvement in women treated for breast cancer $[48,49]$.

\section{Physical activity/rehabilitation}

To prevent weight gain, but also for its many beneficial effects on psychological and physical aspects, a regular physical activity is recommended for patients treated for breast cancer $[10,37,50,51]$. Inactivity should be avoided and daily activities should be resumed as soon as possible after surgery and during adjuvant cancer treatment [10, 45, 51]. More specifically, concerning aerobic training, 20 to $60 \mathrm{~min}$ of exercise at a moderate intensity (50-75\% of the maximal heart rate) are recommended 3 to 5 times per week [10, 45, 51, 52]. For resistance training, it is recommended to follow a supervised program of approximately 2 to 3 sets of 8 to 15 repetitions with a very low load at baseline, 2 to 3 times a week. The resistance can be increased in small increments without any upper limit, but it is important to monitor the appearance of symptoms of the arm and/or shoulder such as a lymphedema and to reduce the resistance or stop the exercises according to the complications observed [10, 45, 52]. Finally, with regard to stretching, it is advisable to stretch the large muscle groups for 10 to $30 \mathrm{~s} 2$ to 3 times per week [10, 45].

Many clinical trials and systematic reviews have evaluated the benefits of physical training in patients being treated for breast cancer. Although these studies differ according to timing of the intervention (during or after treatment), location (home or institution), duration, frequency and type of exercises performed and thus although no consensus is yet clear on these parameters, many benefits have been objectified. Thus, in view of the literature, physical activity/rehabilitation can have a positive impact on the quality of life of breast cancer patients [10, 37, 50, 53-65], on fatigue [10, 37, 50, 54, 56, 57, 60, 63, 66-68], on cardiopulmonary function (resting and/or maximal heart rate and maximal oxygen consumption) [10, 50, 53, $57,58,60,61,67-74]$, on weight and body composition (body weight, body mass index and/or percentage of body fat or lean mass) $[10,50,57,61,66,69,71,75-77]$ and on the psychological, emotional and physical well-being (such as anxiety, depression, body-image) $[10,37,50,54,55,57$, $60,61,67,72,75]$.

\section{Physiotherapy interventions}

Lymphedema is a side effect often encountered as a result of breast cancer surgery and/or radiotherapy. The physiotherapist, with a manual lymphatic drainage associated with the implementation of compression bandages and/or compression therapy, skin care and remedial exercises, may help to reduce swelling, but also pain and heaviness [12, 78]. Moreover, early physiotherapy interventions (including manual lymphatic drainage, massage 
of scar tissue, shoulder exercises, and educational strategy) also seem to be effective in the prevention of lymphedema [78].

Finally, all these interventions have shown in the literature the benefits they could bring as supportive care, but all should not always be prescribed to all patients. These supportive care modalities should be administered by qualified and experienced providers which take into account the risk-benefit ratio for each therapy, the patients' clinical characteristics (such as stage of disease, the overall goal of anticancer therapy, patient performance status and patient adherence), the communication with all health-care providers involved in the patient's care and also the patient preference [38].

\section{Conclusions}

Due to its high incidence and the side effects experienced as a result of the disease and its treatment, breast cancer constitutes a real public health problem and can be considered as a chronic condition. As side effects affect physical functions and the psychological status, social situation, body composition and well-being of the patient, a multidisciplinary and individualized supportive care is needed in addition to the anticancer therapy. The benefits of various supportive care interventions are already established, but studies are still needed to clearly determine the best modalities of application and the indications based on patient characteristics.

\section{Acknowledgement}

Not applicable.

\section{Funding}

The authors declare that they have no source of funding for the research reported.

\section{Availability of data and materials}

Data sharing not applicable to this article as no datasets were generated or analysed during the current study.

\section{Authors' contributions}

AFL drafted the manuscript. GJ, MD, JMC and DM revised it critically and helped to draft. All authors read and approved the final manuscript.

\section{Competing interests}

The authors declare that they have no competing interests.

\section{Consent for publication}

Not applicable.

\section{Ethics approval and consent to participate} Not applicable.

\footnotetext{
Author details

'Department of Sports and Rehabilitation Sciences, Liège University, Allée des Sports 4 - B21, 4000 Liège, Belgium. ${ }^{2}$ Department of Physical Medicine, Liège University Hospital, Avenue de l'Hôpital 1 - CHU B35, 4000 Liège, Belgium. ${ }^{3}$ Division of Medical Oncology, Liège University Hospital, Liège University, Avenue de l'Hôpital 1 - CHU B35, 4000 Liège, Belgium. ${ }^{4}$ Department of Clinical Hematology, Liège University Hospital, Avenue de I'Hôpital 1 - CHU B35, 4000 Liège, Belgium.
}

Received: 7 October 2016 Accepted: 17 October 2016

Published online: 05 December 2016

\section{References}

1. Curado MP. Breast cancer in the world: Incidence and mortality. Salud Publica Mex. 2011:53:372-84.

2. Renard F, Van Eycken L, Arbyn M. High burden of breast cancer in Belgium: recent trends in incidence (1999-2006) and historical trends in mortality (1954-2006). Arch Public Heal. 2011;69:2.

3. Bray F, Mccarron P, Parkin DM. The changing global patterns of female breast cancer incidence and mortality. Breast Cancer Res. 2004;6:229-39.

4. Thomson C, Brewster D, Dewar J, Twelves C. Improvements in survival for women with breast cancer in Scotland between 1987 and 1993. Eur J Cancer. 2004;40:743-53.

5. Abdulrahman GO, Rahman GA. Epidemiology of breast cancer in Europe and Africa. J Cancer Epidemio. 2012;2012:1-6.

6. Verkooijen HM, Rapiti E, Bouchardy C. Patients' refusal of surgery strongly impairs. Ann Surg. 2005;242:276-80

7. El-tamer MB, Ward BM, Schifftner T. Morbidity and mortality following breast cancer surgery in women national benchmarks for standards of care. Ann Surg. 2007;245:665-71.

8. Montazeri A. Health-related quality of life in breast cancer patients : a bibliographic review of the literature from 1974 to 2007. J Exp Clin Cancer Res. 2008;27:32.

9. Engel J, Kerr J, Schlesinger-Raab A, Sauer H, Holzel D. Quality of life following breast-conserving therapy or mastectomy: results of a 5-year prospective study. Breast J. 2004;10:223-31.

10. Schmitz KH, Courneya KS, Matthews C, Demark-Wahnefried W, Galvão D, Pinto BM, et al. American college of sports medicine roundtable on exercise guidelines for cancer survivors. Med Sci Sports Exerc. 2010;42:1409-26.

11. Roses DF, Brooks AD, Harris MN, Shapiro RL, Mitnick J. Complications of level I and II axillary dissection in the treatment of carcinoma of the breast. Ann Surg. 1999;230:194-201.

12. Ezzo J, Manheimer E, Ml M, Dm H, Weiss R, Ki J, et al. Manual lymphatic drainage for lymphedema following breast cancer treatment. Cochrane Database Syst Rev. 2015;5:CD003475.

13. Shah C, Vicini FA. Breast cancer-related arm lymphedema: Incidence rates, diagnostic techniques, optimal management and risk reduction strategies. Int J Radiat Oncol Biol Phys. 2011;81:907-14.

14. Shapiro $C L$, Recht A. Side effects of adjuvant treatment of breast cancer. N Engl J Med. 2001;344:1997-2008.

15. Sjövall K, Strömbeck G, Löfgren A, Bendahl P, Gunnars B. Adjuvant radiotherapy of women with breast cancer - information, support and side-effects. Eur J Oncol Nurs. 2010;14:147-53.

16. Meyns $M$, Jansen $N$, Deneufbourg JM. Place de la radiothérapie dans le traitement du cancer du sein. Indications actuelles et perspectives. Rev Med Liege. 2006;61:623-31.

17. Lundstedt D. Long - Term Symptoms after Breast Cancer Radiotherapy. Gothenburg: University of Gothenburg; 2012.

18. Tierney AJ, Leonard RCF, Taylor J, Closs SJ, Chetty U, Rodger A. Side effects expected and experienced by women receiving chemotherapy for breast cancer. BMJ. 1991;302:272.

19. de Jong N, Candel MJJM, Schouten HC, Abu-Saad HH, Courtens AM. Course of mental fatigue and motivation in breast cancer patients receiving adjuvant chemotherapy. Ann Oncol. 2005;16:372-82.

20. Tchen N, Juffs HG, Downie FP, Yi Q-L, Hu H, Chemerynsky l, et al. Cognitive function, fatigue, and menopausal symptoms in women receiving adjuvant chemotherapy for breast cancer. J Clin Oncol. 2003;21:4175-83.

21. de Jong N, Courtens AM, Abu-Saad HH, Schouten HC. Fatigue in patients with breast cancer receiving adjuvant chemotherapy: a review of the literature. Cancer Nurs. 2002;25:283-97.

22. Baena-Canada J, Estalella-Mendoza S, Gonzalez-Guerrero M, Exposito-Alvarez I, Rosado-Varela P, Benitez-Rodriguez E. Influence of clinical and biographical factors on the quality of life of women with breast cancer receiving adjuvant chemotherapy. Rev Calid Asist. 2011;26:299-305.

23. Bower JE, Ganz PA, Desmond KA, Rowland JH, Meyerowitz BE, Belin TR. Fatigue in Breast Cancer Survivors: occurrence, correlates, and impact on quality of life. J Clin Oncol. 2000;18:743-53.

24. Partridge AH, Burstein HJ, Winer EP. Side effects of chemotherapy and combined chemohormonal therapy in women with early-stage breast cancer. J Natl Cancer Inst Monogr. 2001;02115:135-42. 
25. Urquhart LM. Taxanes as a first-line systemic treatment in metastatic breast cancer. Clin J Oncol Nurs. 2011;17:15-21.

26. Tonezzer T, Pereira C, Filho U, Marx A. Hormone therapy/adjuvant chemotherapy induced deleterious effects on the bone mass of breast cancer patients and the intervention of physiotherapy: a literature review. Eur J Gynaecol Oncol. 2010;31:262-7.

27. So WKW, Marsh G, Ling WM, Leung FY, Lo JCK, Yeung M, et al. Anxiety, depression and quality of life among Chinese breast cancer patients during adjuvant therapy. Eur J Oncol Nurs. 2010;14:17-22.

28. Fallowfield L, Cella D, Cuzick J, Francis S, Locker G, Howell A. Quality of life of postmenopausal women in the arimidex, tamoxifen, alone or in combination (ATAC) adjuvant breast cancer trial. J Clin Oncol. 2004;22:4261-71.

29. Campone M, Berton-Rigaud D, Bourbouloux E, Sophie S, Zanetti A, Frenel J. Her2 positive breast cancer: practices. Bull Cancer. 2011;98:154-63.

30. Beuzeboc P. Indications of Herceptin in breast cancer treatment. Gynécologie Obs Fertil. 2004;32:164-72.

31. Lin NU, Dieras V, Paul D, Lossignol D, Christodoulou C, Stemmler H, et al. Multicenter phase II study of lapatinib in patients with brain metastases from HER2-positive breast cancer. Clin Cancer Res. 2009:15:1452-9.

32. Molnar-stanciu D, Guimas V, Bensalem A, Thiery-vuillemin A. Targeted therapy and breast cancer: state of the art. Pathol Biol. 2012;60:254-63.

33. Loibl S, Lederer B. The importance of supportive care in breast cancer patients. Breast Care. 2014;9:230-1.

34. Cherny N, Catane R, Kosmidis P. ESMO takes a stand on supportive and palliative care. Ann Oncol. 2003;14:1335-7.

35. Ganz PA, Har C, Gralow JR, Distelhorst SR, Albain KS, Andersen BL, et al. Supportive care after curative treatment for breast cancer (survivorship care): Resource allocations in low- and middle-income countries. A Breast Health Global Initiative 2013 consensus statement. The Breast. 2013; 2013(22):606-15.

36. Faller H, Schuler M, Richard M, Heckl U, Weis J, Ku R, et al. Effects of psycho-oncologic interventions on emotional distress and quality of life in adult patients with cancer: systematic review and meta-analysis. J Clin Oncol. 2013;31:782-93.

37. Duijts SFA, Faber MM, Oldenburg HSA, Beurden MV. Effectiveness of behavioral techniques and physical exercise on psychosocial functioning and health-related quality of life in breast cancer patients and survivors - a meta-analysis. Psychooncology. 2011;20:115-26.

38. Greenlee H, Balneaves LG, Carlson LE, Cohen M, Deng G, Hershman D, et al. Clinical practice guidelines on the use of integrative therapies as supportive care in patients treated for breast cancer. J Natl Cancer Inst Monogr. 2014;50:346-58.

39. Galway K, Black A, Cantwell M, Cardwell C, Mills M, Donnelly M. Psychosocial interventions to improve quality of life and emotional wellbeing for recently diagnosed cancer patients. Cochrane Database Syst Rev. 2012;11:CD007064.

40. Brandão T, Schulz MS, Matos PM. Psychological intervention with couples coping with breast cancer : A systematic review. Psychol Health. 2014;29:491-516.

41. Stagl JM, Bouchard LC, Lechner SC, Blomberg BB. Long-Term Psychological Benefits of Cognitive-Behavioral Stress Management for Women With Breast Cancer : 11-Year Follow-Up of a Randomized Controlled Trial. Cancer. 2015;121:1873-81.

42. Matsuda A, Yamaoka K. Effectiveness of psychoeducational support on quality of life in early-stage breast cancer patients : a systematic review and meta-analysis of randomized controlled trials. Qual Life Res. 2014;23:21-30.

43. Berger AM, Sankaranarayanan J, Watanabe-galloway S. Current methodological approaches to the study of sleep disturbances and quality of life in adults with cancer: a systematic review. Psychooncology. 2007; 16:401-20.

44. Cohen M, Fried G. Comparing relaxation training and cognitive-behavioral group therapy for women with breast cancer. Res Soc Work Pract. 2007;17:313-23.

45. Rock C, Doyle C, Demark-Wahnefried W, Meyerhardt J, Courneya K, Schwartz $A$, et al. Nutrition and physical activity guidelines for cancer survivors. CA Cancer J Clin. 2012;62:242-74.

46. Caan BJ, Kwan ML, Hartzell G, Castillo A, Slattery ML, Sternfeld B, et al. Pre-diagnosis body mass index, post-diagnosis weight change, and prognosis among women with early stage breast cancer. Cancer Causes Control. 2008;19:1319-28.

47. Rock C. Diet and breast cancer: can dietary factors influence survival? J Mammary Gland Biol Neoplasia. 2003:8:119-32.
48. Harrigan M, Cartmel B, Loft E, Sanft T, Chagpar AB, Zhou Y, et al. Randomized trial comparing telephone versus in-person weight loss counseling on body composition and circulating biomarkers in women treated for breast cancer: the Lifestyle, Exercise, and Nutrition (LEAN) Study. J Clin Oncol. 2016:34:669-79.

49. Schiavon CC, Vieira FGK, Ceccatto V, De Liz S, Cardoso AL, Sabel C, et al. Nutrition education intervention for women with breast cancer: effect on nutritional factors and oxidative stress. J Nutr Educ Behav. 2015;47:2-9.

50. McNeely ML, Campbell KL, Rowe BH, Klassen TP, Mackey JR, Courneya KS. Effects of exercise on breast cancer patients and survivors: a systematic review and meta-analysis. CMAJ. 2006;175:34-41.

51. Doyle C, Kushi LH, Byers T, Courneya KS, Demark-Wahnefried W, Grant B, et al. Nutrition and physical activity during and after cancer treatment: an American Cancer Society guide for informed choices. CA Cancer J Clin. 2006:56:323-53.

52. Hayes SC, Spence RR, Galvão DA, Newton RU. Australian Association for Exercise and Sport Science position stand: Optimising cancer outcomes through exercise. J Sci Med Sport. 2009;12:428-34.

53. Campbell A, Mutrie N, White F, McGuire F, Kearney N. A pilot study of a supervised group exercise programme as a rehabilitation treatment for women with breast cancer receiving adjuvant treatment. Eur J Oncol Nurs. 2005;9:56-63.

54. Hwang JH, Chang HJ, Shim YH, Park WH, Park W, Huh SJ. Effects of Supervised Exercise Therapy in Patients Receiving Radiotherapy for Breast Cancer. Yonsei Med J. 2008;49:443-50.

55. Haines TP, Sinnamon P, Pratt T, Smith A. Multimodal exercise improves quality of life of women being treated for breast cancer, but at what cost? Randomized trial with economic evaluation. Breast Cancer Res Treat. 2010;124:163-75.

56. Wang Y, Boehmke M, Wu YB, Dickerson SS, Fisher N. Effects of a 6-Week Walking Program on Taiwanese Women Newly Diagnosed With Early-Stage Breast Cancer. Cancer Nurs. 2011;34:1-13.

57. Courneya KS, Mackey JR, Bell GJ, Jones LW, Field CJ, Fairey AS. Randomized controlled trial of exercise training in postmenopausal breast cancer survivors: cardiopulmonary and quality of life outcomes. J Clin Oncol. 2003;21:1660-8.

58. Basen-Engquist K, Taylor CLC, Rosenblum C, Smith MA, Shinn EH, Greisinger A, et al. Randomized pilot test of a lifestyle physical activity intervention for breast cancer survivors. Patient Educ Couns. 2006;64:225-34.

59. Cho OH, Yoo YS, Kim NC. Efficacy of comprehensive group rehabilitation for women with early breast cancer in South Korea. Nurs Heal Sci. 2006;8:140-6.

60. Daley AJ, Crank H, Saxton JM, Mutrie N, Coleman R, Roalfe A. Randomized trial of exercise therapy in women treated for breast cancer. J Clin Oncol. 2007:25:1713-21.

61. Herrero F, San Juan AF, Fleck SJ, Balmer J, Pérez M, Cañete S, et al. Combined aerobic and resistance training in breast cancer survivors: A randomized, controlled pilot trial. Int J Sports Med. 2006;27:573-80.

62. Ohira T, Schmitz KH, Ahmed RL, Yee D. Effects of weight training on quality of life in recent breast cancer survivors: The weight training for breast cancer survivors (WTBS) study. Cancer. 2006;106:2076-83.

63. Vallance JKH, Courneya KS, Plotnikoff RC, Yasui Y, Mackey JR. Randomized controlled trial of the effects of print materials and step pedometers on physical activity and quality of life in breast cancer survivors. J Clin Oncol. 2007:25:2352-9.

64. Speck RM, Courneya KS, Mâsse LC, Duval S, Schmitz KH. An update of controlled physical activity trials in cancer survivors : a systematic review and meta-analysis. J Cancer Surviv. 2010;4:87-100.

65. Buffart LM, Galvao DA, Brug J, Chinapaw MJM, Newton RU. Evidence-based physical activity guidelines for cancer survivors: Current guidelines, knowledge gaps and future research directions. Cancer Treat Rev. 2014;40:327-40.

66. Pinto BM, Frierson GM, Rabin C, Trunzo JJ, Marcus BH. Home-based physical activity intervention for breast cancer patients. J Clin Oncol. 2005;23:3577-87.

67. Mock V, Dow KH, Meares CJ, Grimm PM, Dienemann JA, Haisfield-Wolfe ME, et al. Effects of exercise on fatigue, physical functioning, and emotional distress during radiation therapy for breast cancer. Oncol Nurs Forum. 1997;24:991-1000.

68. Pinto BM, Clark MM, Maruyama NC, Feder SI. Psychological and fitness changes associated with exercise participation among women with breast cancer. Psychooncology. 2003;12:118-26.

69. Courneya KS, Segal RJ, Mackey JR, Gelmon K, Reid RD, Friedenreich CM, et al. Effects of aerobic and resistance exercise in breast cancer patients receiving adjuvant chemotherapy: A multicenter randomized controlled trial. J Clin Oncol. 2007;25:4396-404. 
70. Schwartz AL, Winters-Stone K, Gallucci B. Exercise effects on bone mineral density in women with breast cancer receiving adjuvant chemotherapy. Oncol Nurs Forum. 2007;34:627-33.

71. Schwartz AL, Winters-stone K. Effects of a 12-month randomized controlled trial of aerobic or resistance exercise during and following cancer treatment in women. Phys Sportsmed. 2009;37:62-7.

72. Thorsen L, Skovlund E, Strømme SB, Hornslien K, Dahl AA, Fosså SD. Effectiveness of physical activity on cardiorespiratory fitness and healthrelated quality of life in young and middle-aged cancer patients shortly after chemotherapy. J Clin Oncol. 2005;23:2378-88.

73. Nikander R, Sievänen H, Ojala K, Oivanen T, Kellokumpu-Lehtinen P-L, Saarto T. Effect of a vigorous aerobic regimen on physical performance in breast cancer patients - a randomized controlled pilot trial. Acta Oncol. 2007;46:181-6.

74. Jones LW, Liang Y, Pituskin EN, Battaglini CL, Scott JM, Hornsby WE, et al. Effect of exercise training on peak oxygen consumption in patients with cancer: a meta-analysis. Oncologist. 2011;16:112-20.

75. Segal R, Evans W, Johnson D, Smith J, Colletta S, Gayton J, et al. Structured exercise improves physical functioning in women with stages I and II breast cancer: results of a randomized controlled trial. J Clin Oncol. 2001;19:657-65.

76. Schmitz KH, Ahmed RL, Hannan PJ, Yee D. Safety and efficacy of weight training in recent breast cancer survivors to alter body composition, insulin, and insulin-like growth factor axis proteins safety and efficacy of weight training in recent breast cancer survivors to alter body composition. Cancer Epidemiol Biomarkers Prev. 2005;14:1672-80.

77. Demark-Wahnefried W, Clipp EC, Lipkus IM, Lobach D, Snyder DC, Sloane R, et al. Main outcomes of the FRESH START trial: A sequentially tailored, diet and exercise mailed print intervention among breast and prostate cancer survivors. J Clin Oncol. 2007;25:2709-18.

78. Merchant SJ, Chen SL. Prevention and management of lymphedema after breast cancer treatment. Breast J. 2015;21:276-84.

\section{Submit your next manuscript to BioMed Central and we will help you at every step:}

- We accept pre-submission inquiries

- Our selector tool helps you to find the most relevant journal

- We provide round the clock customer support

- Convenient online submission

- Thorough peer review

- Inclusion in PubMed and all major indexing services

- Maximum visibility for your research

Submit your manuscript at www.biomedcentral.com/submit 